\title{
Pharmacogenetics implementation in the clinics: information and guidelines for germline variants
}

\author{
Gladys Olivera ${ }^{1,2}$, Luis Sendra',2, María José Herrero ${ }^{1,2}$, Pablo Berlanga $^{3}$, Pablo Gargallo $^{4}$, Yania Yáñez ${ }^{4}$, \\ Andrea Urtasun ${ }^{4}$, Jaime Font de Mora ${ }^{5}$, Victoria Castel ${ }^{4}$, Adela Cañete ${ }^{4}$, Salvador F. Aliño ${ }^{1,2}$ \\ 'Pharmacogenetics Platform, Instituto de Investigación Sanitaria la Fe, Valencia 46026, Spain. \\ 2Department of Pharmacology, University of Valencia, Valencia 46010, Spain. \\ ${ }^{3}$ Department of Pediatric and Adolescent oncology, Institute Gustave Roussy Center, Villejuif 94800, France. \\ ${ }^{4}$ Pediatric Oncology Unit, Hospital Universitario y Politécnico la Fe, Valencia 46026, Spain. \\ ${ }^{5}$ Pediatric Clinical and Translational Research in Cancer, Instituto de Investigación Sanitaria la Fe, Valencia 46026, Spain.
}

Correspondence to: Dr. María José Herrero, Pharmacogenetics Platform, Instituto de Investigación Sanitaria la Fe, Valencia 46026, Spain; Department of Pharmacology, University of Valencia, Valencia 46010, Spain. E-mail: maria.jose.herrero@uv.es

How to cite this article: Olivera G, Sendra L, Herrero MJ, Berlanga P, Gargallo P, Yáñez Y, Urtasun A, Font de Mora J, Castel V, Cañete A, Aliño SF. Pharmacogenetics implementation in the clinics: information and guidelines for germline variants. Cancer Drug Resist 2019;2:53-68. http://dx.doi.org/10.20517/cdr.2018.25

Received: 8 Nov 2018 First Decision: 12 Nov 2018 Revised: 18 Jan 2019 Accepted: 31 Jan 2019 Published: 19 Mar 2019

Science Editor: Enrico Mini Copy Editor: Cai-Hong Wang Production Editor: Huan-Liang Wu

\begin{abstract}
The aim of this work was to supply an overview of the germline Pharmacogenetics that can be already implemented in the oncology clinical practice. An explanation of the three pillars considered necessary for determining which genetic polymorphisms should be used has been provided. These are PharmGKB single nucleotide polymorphism (SNP)-Drug Clinical Annotations with levels of evidence 1 or 2; the genetic information provided in the drug labels by the drug regulatory main agencies (Food and Drug Administration and European Medicines Agency, mainly); and the guidelines elaborated by international expert consortia (mainly Clinical Pharmacogenetics Implementation Consortium and Dutch Pharmacogenetics Working Group). A summary of the relevant SNPs and the recommendations on how to apply their results has also been compiled.
\end{abstract}

Keywords: Polymorphisms, Pharmacogenetic, PharmGKB, guidelines, oncology, clinical implementation

\section{INTRODUCTION}

Pharmacogenetics (PGx) is one of the cornerstones of personalized medicine. It aims to foresee, upon the patient's genetic characteristics, what drug and which dose would offer the highest therapeutic benefit and/ or the lowest probability of adverse effects. The most abundant genetic variants influencing PGx are the

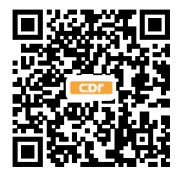


single nucleotide polymorphisms (SNPs), accounting for approximately $90 \%$ of human genome variability ${ }^{[1,2]}$. However, key variants influencing PGx include also genomic insertions, deletions and repeats, and genetic copy number variations, in addition to SNP. The aim of this review is to provide an easy-to-interpret summary of the drug-germline polymorphisms pairs (mainly SNPs) that currently can be used to help in oncologists in the therapeutic decision making.

PGx is related with pharmacology and thus, the molecular knowledge of drugs' transporters, metabolizers and mechanism of action are required ${ }^{[1]}$. Adverse drug reactions (ADRs) as well as drug efficacy are associated with particular genetic variants of each individual, related to the genes coding for all the components interacting with the drug inside the patients' body. For this reason, clinical practice must turn into personalized and precision medicine $e^{[2-4]}$. However, how to implement PGx in the daily routine is not free of difficulties and physicians do need the support of rigorous and evidence-based information. The axis of this work consists in a review of the available associations and guidelines of drug/germline polymorphisms, with the highest evidence level, that could be applied within the clinical practice in pediatric and adult oncologic patients. Tumor (somatic) genetic variants are out of the scope of this review. The aim is providing clinicians with a helpful tool for therapeutic prescribing, regarding the individual patient, which can be useful even before having tumor tissue analyses available.

Most of the existing PGx information is compiled in PharmGKB ${ }^{[3]}$, a free access database created, curated and managed by the University of Stanford and funded by US National Institutes of Health (NIH/NIGMS). PharmGKB data are under a Creative Commons license. It counts with a group of experts working on the dissemination of knowledge about the impact of human genetic variation on drug responses and on the translation of PGx into clinical practice.

\section{SOURCES OF INFORMATION}

In www.pharmGKB.org website an extensive and constantly updated compilation of the PGx knowledge can be found ${ }^{[3]}$. It is mainly based on the results of the articles published worldwide, mainly included in PubMed database. In our case, our focus is the subset of data that is ready to be used in the clinical practice, so our references on this database will be the following:

PGx Prescribing Info: this part contains drug dosing guidelines that take into consideration patient genotype, published by the Clinical Pharmacogenetics Implementation Consortium (CPIC) ${ }^{[5]}$, the Royal Dutch Association for the Advancement of Pharmacy - Pharmacogenetics Working Group (DPWG, manually curated by PharmGKB) $)^{[6]}$, or other professional society (PRO, manually curated by PharmGKB $)^{[7]}$.

Drug Labels: Regulatory agencies as the US Food and Drug Administration (FDA) ${ }^{[8]}$, the European Medicines Agency (EMA) ${ }^{[9]}$, the Pharmaceuticals and Medical Devices Agency (PMDA) from Japan ${ }^{[10]}$ and Health Canada Santé Canada (HCSC ${ }^{[11]}$ have included the recommendation of a genetic test prior to the use of many drugs. The drug label indicates if the test is required, recommendable, actionable or simply informative ${ }^{[3]}$.

Clinical Annotations: drug/polymorphism relationships graded with a "Level of Evidence". This scientific evidence rank is assigned by the PharmGKB experts from 1 to $4(1 \mathrm{~A}, 1 \mathrm{~B}, 2 \mathrm{~A}, 2 \mathrm{~B}, 3$ and 4$), 1 \mathrm{~A}$ being the highest. In level $1 \mathrm{~A}$ annotations, the variant-drug combination is included in a CPIC or a PGx guide approved by the medical society or implemented in a PGRN (Pharmacogenomics Research Network) site or in another important health system. In level 1B annotations, the preponderance of evidence shows an association that replicates in more than one cohort with significant $P$-values, and preferably will have a strong effect size. Level 2 includes variants with moderate evidence. Level $2 \mathrm{~A}$ marks annotations for variant- 
drug combinations that qualify for level $2 \mathrm{~B}$ where the variant is within a very important pharmacogene as defined by PharmGKB, so functional significance is more likely. In Level $2 \mathrm{~B}$ variant-drug combinations, the association must be replicated but there may be some studies that do not show statistical significance, and/ or the effect size may be small. Level 3 and level 4 clinical associations are not strong enough to be used for clinical translation, under our point of view. Level 3 annotation based on a single significant (not yet replicated) study or annotation for a variant-drug combination evaluated in multiple studies but lacking clear evidence of an association; and finally, level 4 annotations are based on a case report, non-significant study or in vitro, molecular or functional assay evidence only ${ }^{[7]}$.

\section{DRUGS AND GUIDELINES}

Guidelines are not always easy to interpret, mainly if the reader is not used to the usual terms and nomenclature in PGx. It is crucial that the recommendations arrive to the prescribing clinicians in a rigorous but at the same time, simple and easy-to-interpret manner, otherwise clinical implementation of PGx would be hardly impossible.

Following with our aim, we focus now on the existing PGx guidelines for chemotherapy treatment and some associated drugs. Table 1 summarizes the content of CPIC and DPWG published documents, being these, and specially the first, the most active and experienced consortia in providing this kind of tools for PGx translation to the clinic. The description of the procedures employed by each consortium to evaluate the evidence and apply recommendations is described in a couple of publications ${ }^{[12,13]}$. Currently, and being aware that these consortia employ different criteria for nomenclature and also for rising recommendations, they are making efforts for harmonization, with a descriptive publication just comparing their statements and showing the differences as a first step ${ }^{[14]}$.

Other guidelines, elaborated by other professional groups, are commented afterwards in the text. These guidelines have not received the approval or reached a consensus with other societies or consortia, so the robustness of the way they evaluate the evidences ${ }^{[15]}$ is not recognized in the manner that CPIC is.

Again, it is very important to remark that Table 1 aims to provide a rigorous but user-friendly content, and therefore, translation of asterisk or phenotype-way nomenclatures into "rs" SNP nomenclature is given when possible. Also, some of the guidelines include very low frequent variants that are not considered in Table 1 either, so if a deeper detail is needed, the original guidelines referenced in this work should be consulted.

Regarding CYP2D6, it is necessary to state that it is one of the most complicated genes to analyze in terms of genotyping and in knowing with high certainty, the genotype-phenotype correlation. Many groups are working on this point worldwide, trying to clearly identify which genetic variants lead to poor, intermediate, normal or ultrarapid metabolizers (UM). This gene is highly polymorphic, but not only regarding SNPs content, but also in duplications, deletions, etc. Drug-drug interactions and ethnic variability are very important for every pharmacogene, but we could say that for $C Y P_{2} D 6$ the impact is the highest ${ }^{[16]}$. That is why in Table 1, the information regarding ondansetron, oxycodone, tamoxifen and tramadol has been kept with the typical CYP2D6 nomenclature including haplotypes and asterisks.

\section{Thiopurines and TPMT}

Thiopurine drugs such as azathioprine (AZA), 6-mercaptopurine (6-MP) and 6-thioguanine, are cytotoxic drugs employed in the treatment of severe diseases as childhood acute lymphoblastic leukemia and inflammatory bowel disease ${ }^{[23]}$. AZA is converted almost completely to 6-MP through a non-enzymatic reaction within the liver ${ }^{[24]}$. 
Table 1. Summary of the recommendations provided in CPIC and DPWG guidelines for drugs employed in oncology

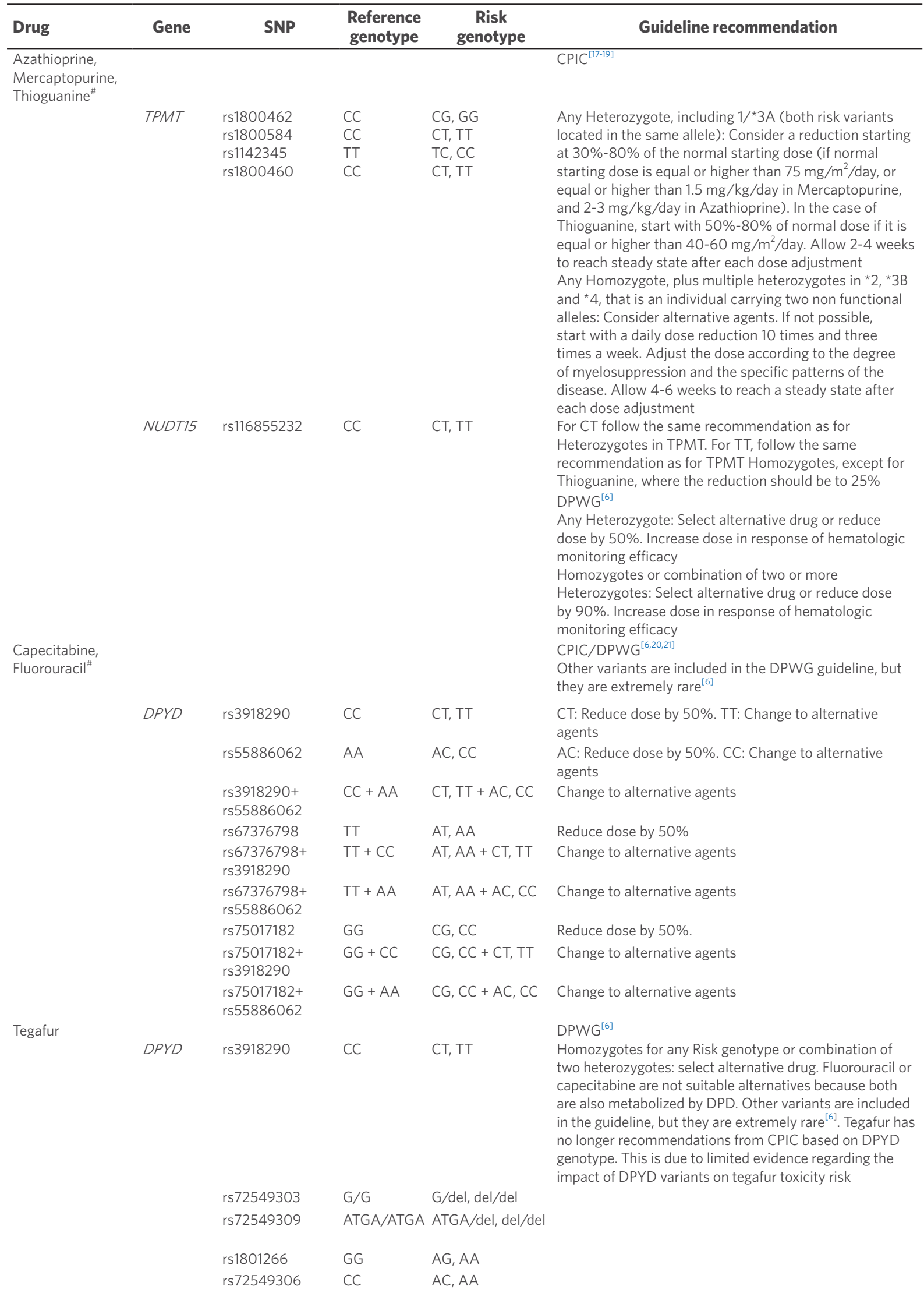




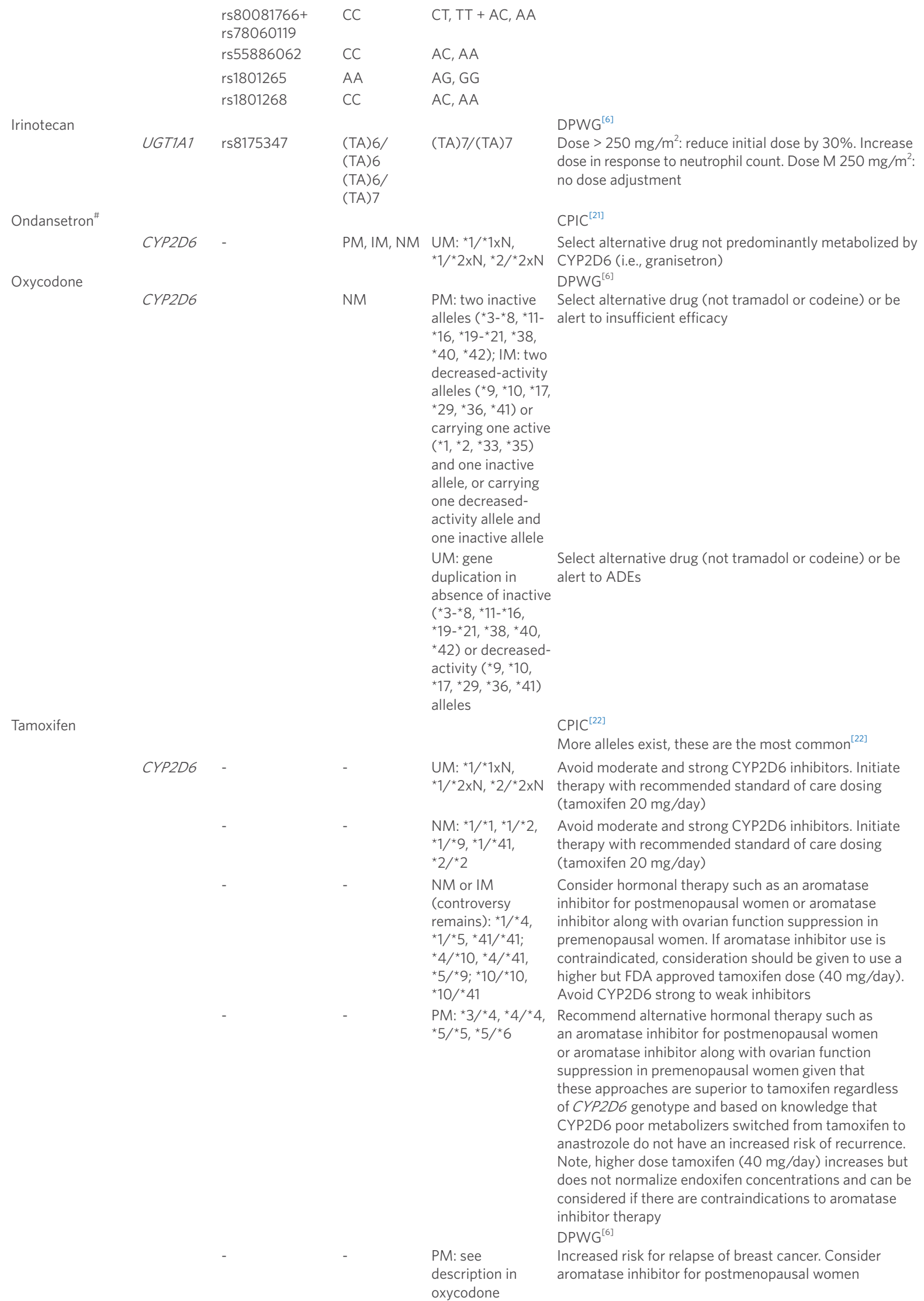




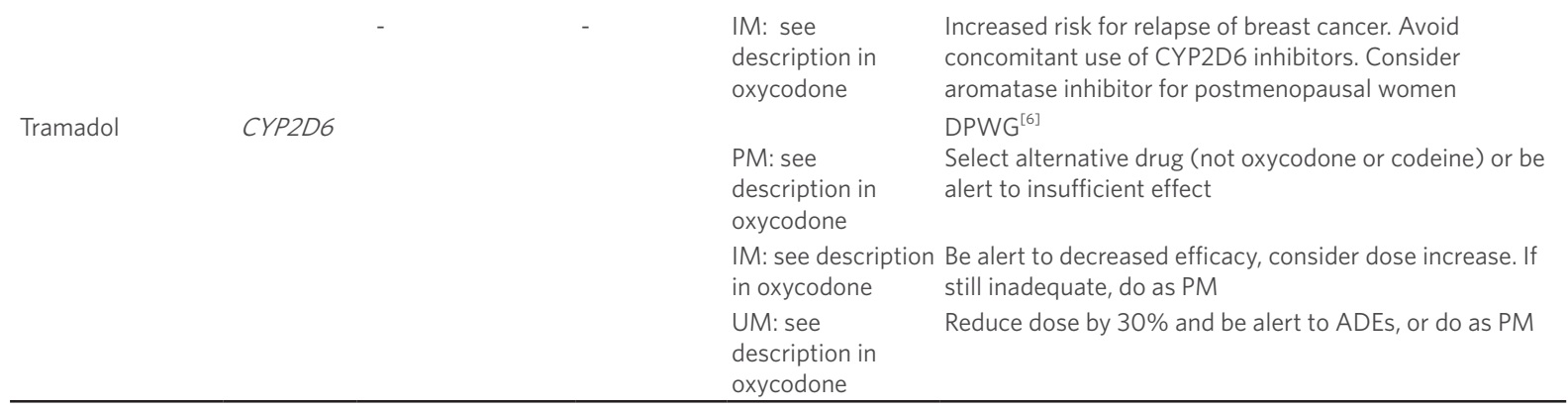

A summary of the published guidelines is shown in this table, translating the information to single SNPs when possible. The original guidelines, especially from CPIC, are much more extensive, so this table is only a comprehensive approach, useful for the majority of cases, but deeper details must be consulted in the original publications. \#Applicable to pediatrics. Classical asterisks nomenclature: ${ }^{*} 1$ is always considered the reference genotype. TPMT: ${ }^{\star} 2$ equivalent to rs $1800462 ;{ }^{*} 3 \mathrm{~A}$ equivalent to ${ }^{\star} 3 \mathrm{~B}+{ }^{\star} 3 \mathrm{C}$; ${ }^{*} 3 \mathrm{~B}$ equivalent to rs 1800460 ; ${ }^{\star} 3 \mathrm{C}$ equivalent to rs1142345; ${ }^{4} 4$ equivalent to rs1800584. NUDT15: ${ }^{3} 3$ equivalent to rs116855232. UGT1A1: ${ }^{\star 2} 28$ equivalent to rs8175347 (this is not a real SNP, but a short tandem repeat polymorphism). DPYD at CPIC guideline: IM, one normal function + one no function, or one decreased function, or two decreased function alleles; PM, two no function, or one no function + one decreased function. No function: c.1905+1G>A equivalent to rs3918290 and DPYD*2A; c.1679 T>G equivalent to rs55886062 and DPYD*13; Decreased function: c.2846 A>T equivalent to rs67376798; c.1129-5923 C>G equivalent to rs75017182. CYP2D6: Date of access to CPIC-DPWG-PharmGKB for guidelines: 15 January 2019. ADE: Adverse Drug Event; UM: ultrarapid metabolizer; NM: normal metabolizer; IM: intermediate metabolizer; PM: poor metabolizer; CPIC: Clinical Pharmacogenetics Implementation Consortium; DPWG: Royal Dutch Association for the Advancement of Pharmacy - Pharmacogenetics Working Group; SNP: single nucleotide polymorphism

These drugs are administered as prodrugs that are converted to thioguanine nucleotides (TGN) by the hypoxanthine guanine phosphoribosyltransferase enzyme. TGNs integrate within DNA and RNA leading to cancer cell death, what is inactivated by cytosolic Thiopurine S-methyltransferase (TPMT) enzyme via S-methylation. For this reason, TPMT gene polymorphisms can alter the enzyme activity and trigger the apoptosis of healthy cells and lead to $\mathrm{ADRs}^{[2]}$.

Alleles ${ }^{*} 2(\mathrm{rs} 1800462, \mathrm{C}>\mathrm{G}),{ }^{*} 3 \mathrm{~A}\left[\right.$ haplotype $\left.{ }^{*} 3 \mathrm{~B}(\mathrm{rs} 1800460, \mathrm{C}>\mathrm{T})+{ }^{*} \mathrm{C}(\mathrm{rs} 1142345, \mathrm{~T}>\mathrm{C})\right],{ }^{*} 3 \mathrm{~B},{ }^{*} 3 \mathrm{C}$ and ${ }^{*} 4$ (rs1800584) are the most common variants and they are estimated to foresee up to $90 \%$ of TPMT function and variability. Other 34 TPMT alleles with low frequencies in different populations have been also described.

Initial doses of treatment with thiopurines are high since they derive from clinical trials performed in general population, where wild type allele has a frequency of $86 \%-97 \%$. These standard doses must be administered only in those patients homozygous for wild type TPMT gene $\left({ }^{*} 1{ }^{*} 1\right)$.

CPIC recommendations indicate that those patients with heterozygous TPMT (one functional allele ${ }^{\star} 1$ and one non-functional allele), should initiate the treatment with $30 \%-80 \%$ of the target dose and been evaluated according to tolerance. Finally, in those patients homozygous for non-functional variants of TPMT it is recommended to begin with $10 \%$ of the target dose and 3 doses a week instead of daily treatment or to change the drug employed ${ }^{[15]}$.

The DPWG provides another clinical guide ${ }^{[6]}$ for the use of thiopurines. They recommend in intermediate metabolizers (IM) heterozygous for TPMT function (containing 1 functional allele as ${ }^{\star} 1,{ }^{*} 1 \mathrm{~S},{ }^{\star} 1 \mathrm{~A}$, and one nonfunctional allele like $\left.{ }^{{ }} 2,{ }^{*} 3 \mathrm{~A}-{ }^{*} 3 \mathrm{D},{ }^{*} 4{ }^{*}{ }^{*} 18\right)$ to select an alternative drug or reduce the dose to $50 \%$ and increase it under efficacy and hematologic surveillance. In poor metabolizers (PM) patients carrying two inactive alleles ( ${ }^{*} 2$, $\left.{ }^{*} 3 \mathrm{~A}-{ }^{*} 3 \mathrm{D},{ }^{*} 4-{ }^{*} 18\right)$ it is recommended to select an alternative drug or to reduce the doses by $90 \%$ and increase it according to the efficacy and hematologic toxicity data obtained by monitoring the patient.

However, there are patients with TPMT wild type genotype that present toxicity when treated with thiopurines. This is most probably due to the existence of other variants involved in thiopurines metabolism 
such as the observed in a GWAS study that correlated the variant rs116855232 $\mathrm{C}>\mathrm{T}$ in NUDT15 gene ${ }^{[25]}$ with myelosuppression in inflammatory bowel disease and acute lymphoblastic leukemia patients treated with thiopurines ${ }^{[26]}$. Different studies correlate the CT or TT genotype with higher toxicity risk and conclude that doses should be reduced ${ }^{[27]}$.

\section{Capecitabine, fluorouracil, tegafur and DPYD}

Fluoropyrimidines, capecitabine, fluorouracil and tegafur, are antimetabolite drugs widely employed in colorectal, aerodigestive tract and breast cancer treatment. Between $10 \%$ and $40 \%$ of the patients with this type of treatment develop severe toxicity (neutropenia, nausea, vomit, diarrhea, stomatitis, mucositis, foot hand syndrome), causing even the death in some cases ${ }^{[28]}$.

The most common cause of fluoropyrimidines toxicity is the lack of the key enzyme for fluorouracil metabolism, dihydropyrimidine dehydrogenase (DPD), which is encoded by DPYD gene. A complete lack of enzyme activity is only present in very few patients. Most patients have a reduced DPD activity due to the genetic risk variant, but not a complete lack of activity since most patients are heterozygous carriers of these variants and thus have one fully functional gene copy. Reduced activity is present in 39\%-61\% of patients with severe toxicity, what highlights its relevance as severe toxicity risk factor ${ }^{[29]}$.

Nowadays, different DPYD gene variants resulting in reduced enzyme function and toxicity risk are known and described. Variants $\mathrm{rs3918290}(\mathrm{G}>\mathrm{A})$ or ${ }^{\star} 2 \mathrm{~A}$ and $\mathrm{rs55886062}(\mathrm{T}>\mathrm{G})$ or ${ }^{\star} 13$ present higher impact in reducing enzyme activity than variants $r 567376798(A>T)$ and $\operatorname{rs75017182}(C>G)$, which are associated with moderately reduced enzyme activity.

According to the CPIC guide ${ }^{[20]}$, the dosing recommendations for fluoropyrimidines are based on individuals genotype, which can be divided in three main groups: normal metabolizers (NM), carrying two normal alleles; IM carrying one normal allele and another one with reduced function, or carrying two alleles with reduced function; and PM, carrying two alleles without function or one non-functional allele and another one with reduced function.

In NM the administration and doses indicated in drug label are recommended. In intermediate metabolizers, it is recommended to reduce the doses by 50\%. Finally, the poor metabolizers are recommended to be treated with therapeutic schemes without 5-fluorouracil.

PharmGKB explains the Drug Agencies information in the drug label indicating that "actionable", means that "the label does not discuss genetic or other testing for gene/protein/chromosomal variants, but does contain information about changes in efficacy, dosage or toxicity due to such variants. The label may mention contraindication of the drug in a particular subset of patients but does not require or recommend gene, protein or chromosomal testing". Labels approved by FDA, EMA, HCSC and PMDA for capecitabine point that those patients with low or absent DPD activity present higher risk of severe or lethal adverse reactions. Fluorouracil does not appear within EMA label.

There is still scarce information about the DPYD gene variants in pediatric patients. However, there is no evidence that these variants could affect the 5 -fluorouracil metabolism in children in a different way to adults.

The DPWG guide for capecitabine and fluorouracil recommend to reduce the dose by $50 \%$ or to change the drug in intermediate metabolizers. For poor metabolizers it is recommended to use an alternative drug too. Tegafur is not an appropriate alternative since it is also a substrate for DPD. 
Tegafur is another fluorpyrimidine that does not present a CPIC recommendation. However, the DPWG guide has a recommendation to poor metabolizers to select an alternative drug, avoiding capecitabine and fluorouracils since they are also metabolized by $\mathrm{DPD}^{[6]}$.

\section{Irinotecan and UGT1A1}

Irinotecan is a hemisynthetic camptothecin mainly used for the treatment of metastatic colorectal cancer, multiform glioblastoma, lung cancer, upper gastrointestinal cancer and pancreas cancer. It is metabolized by the liver to be converted in its active metabolite called SN-38. The SN-38 targets DNA topoisomerase I, stabilizing the cleavable complexes that break the DNA strands and producing the cancerous cells death ${ }^{[30,31]}$.

The UGT1A1 (UDP Glucuronosyltransferase family 1 member A1) enzyme is the responsible of SN-38 inactivation and detoxification. Variants of this gene, such as ${ }^{*} 28$, related with reduced activity of this enzyme, increase the blood levels of SN-38 metabolite and its toxicity ${ }^{[32]}$.

The DPWG guide recommends in patients with a programmed dose of more than $250 \mathrm{mg} / \mathrm{m}^{2}$, to reduce the initial dose of irinotecan by $30 \%$ in homozygous $\left({ }^{*} 28 /{ }^{*} 28\right)$ poor metabolizer patients, and increase it as response to neutrophils count ${ }^{[6]}$. UGT1A1 ${ }^{\star} 28$ has an rs code, rs8175347, but it is not a SNP, instead is a variable number tandem repeat of a dinucleotide TA. There is a surrogate marker, according to the CPIC Atazanavir guideline ${ }^{[33]}$, rs887829 that could be an alternative to analyze this variant.

The French National Network of Pharmacogenetics (RNPGx) and the Group of Clinical Oncopharmacology (GPCO-Unicancer) also presented a guide for ${ }^{\star} 28$ allele ${ }^{[34]}$. When initial doses of irinotecan are between 180 and $230 \mathrm{mg} / \mathrm{m}^{2}$ every $2-3$ weeks homozygous ${ }^{\star} 28 /{ }^{\star} 28$ patients present greater risk of hematologic and digestive toxicity than other genotypes. This guide recommends in this case to reduce the initial doses by $25 \%-30 \%$, especially in those patients with associated risk factors.

When the initial dose is $\geq 240 \mathrm{mg} / \mathrm{m}^{2}$ every $2-3$ weeks, the neutropenia risk is greater. This dose is contraindicated for ${ }^{*} 28{ }^{*} 28$ homozygous patients. It would be possible only in patients homozygous for wild type allele or heterozygous ${ }^{\star} 1{ }^{\star} 28$ without other associated risk factors and under rigorous surveillance (the same in $180-230 \mathrm{mg} / \mathrm{m}^{2}$ ).

FDA and HCSC agencies include recommendations within the drug label, considered actionable. They indicate that the initial dose in ${ }^{\star} 28$ homozygous patients should be considered to be reduced because of the hematologic toxicity risk. It is also recommended not to use neither CYP3A4 inducers during two weeks before initiating irinotecan treatment nor strong CYP3A4 inhibitors one week before and during the irinotecan treatment period. PMDA agency indicates the requirement of genetic test prior to drug administration.

\section{Ondansetron and CYP2D6}

Ondansetron is a serotonin receptor antagonist (5-hydroxitriptamine, subtype 3), employed as antiemetic after chemotherapeutic or surgical treatment. It is metabolized within the liver by cytochrome $\mathrm{P} 450$ enzymes, specifically CYP2D6. This gene presents large amount of variants that can mediate higher or lower efficacy and toxicity ${ }^{[35-37]}$.

The CPIC guide presents recommendations for this drug. It assigns an activity value from 0 to 1 to each functional group. In this sense, this activity value is 0 for poor metabolizers, 0.5 for intermediate metabolizers and 1 for NM. When the allele has more than 1 copy of the functional gene, the activity value is multiplied by the copy number present. Thus, the global activity value is obtained by adding the values of each allele. The patients with an activity value over 2 will be considered $\mathrm{UM}^{[38]}$. 
The recommendations depend, then, upon the group to which each patient belongs. Nowadays, only those patients included within the UM (allelic combinations ${ }^{*} 1 /{ }^{*} 1 \mathrm{xN},{ }^{*} 1 /{ }^{*} 2 \mathrm{xN},{ }^{*} 2 /{ }^{*} 2 \mathrm{xN}$ ) group have recommendations. This guide recommends using an alternative drug not metabolized by CYP2D6. The authors state that there is no reason to expect differences in pediatric oncology, except in newborns ${ }^{[2]]}$.

The recommendations are considered informative by FDA.

\section{Tamoxifen and CYP2D6}

Around $65 \%-75 \%$ of breast cancers express estrogen receptors (ER) or progesterone receptors. This type of cancer can be treated with endocrine therapy such as tamoxifen since it is a selective modulator of estrogen receptor.

Tamoxifen is the unique hormonal agent approved by FDA for pre-menopausal breast cancer prevention, in situ ductal carcinoma treatment and as adjuvant treatment in invasive pre-menopausal metastatic breast cancer.

The metabolization of tamoxifen takes place within the liver and is performed by cytochrome P450 enzymes. The main metabolism mechanism contributes to up to $90 \%$ of the global tamoxifen metabolism and consists in the demethylation of tamoxifen to $\mathrm{N}$-demethyltamoxifen by $\mathrm{CYP} 3 \mathrm{~A}_{4}{ }^{[39]}$, followed by the oxidation to 4-hydroxi-N-demethylmetamoxifen (endoxifen) mediated by CYP2D $6^{[40]}$.

The gene variants are described in https://cpicpgx.org/alleles $/{ }^{[41]}$.

Both CPIC and DPWG have guides for the use of tamoxifen. CPIC guide focuses on the CYP2D6 role in the $\mathrm{ER}+$ cancer breast adjuvant treatment. The recommendations for ultrarapid $\left({ }^{*} 1 /{ }^{*} 1 \mathrm{xN},{ }^{*} 1 /{ }^{*} 2 \mathrm{xN},{ }^{*} 2 /{ }^{*} 2 \mathrm{xN}\right)$ and normal $\left({ }^{\star} 1 /{ }^{\star} 1,{ }^{\star} 1 /{ }^{\star} 2,{ }^{*} 1 /{ }^{*} 9,{ }^{*} 1 /{ }^{*} 41,{ }^{*} 2 /{ }^{*} 2\right)$ metabolizers are to avoid strong and moderate CYP2D6 inhibitors. Treatment can initiate with the standard tamoxifen dose (20 mg/day).

In intermediate metabolizers $\left({ }^{*} 4 /{ }^{*} 10,{ }^{*} 4 /{ }^{*} 41,{ }^{*} 5 /{ }^{*} 9,{ }^{*} 1 /{ }^{*} 4,{ }^{*} 1 /{ }^{*} 5,{ }^{*} 41 /{ }^{*} 41,{ }^{*} 10 /{ }^{*} 10,{ }^{*} 10 /{ }^{*} 41\right)$, aromatase inhibitor therapy should be considered in post-menopausal patients and aromatase inhibitor combined with ovary function suppression in pre-menopausal women since these methods present better outcomes than tamoxifen regardless CYP2D6 genotype ${ }^{[42]}$. In those cases the aromatase inhibitors are contraindicated, tamoxifen doses higher than those approved by the FDA ( $40 \mathrm{mg} /$ day) should be considered. It must be taken into account that highest dose of tamoxifen ( $40 \mathrm{mg} /$ day) increases the concentration of endoxifen without reaching normal levels and then it could be considered if aromatase inhibitors contraindications exist ${ }^{[43,44]}$.

Lastly, in poor metabolizer patients $\left({ }^{{ }^{*}} 3 /{ }^{*} 4,{ }^{*} 4 /{ }^{*} 4,{ }^{*} 5 /{ }^{*} 5,{ }^{*} 5 /{ }^{*} 6\right)$ it is recommended to use an alternative hormonal therapy such as aromatase inhibitor in post-menopausal patients and an aromatase inhibitor combined with ovary function suppression in pre-menopausal women because these strategies are more efficient than tamoxifen regardless the CYP2D6 genotype especially if they are deficient for CYP2D6 metabolism. Changing tamoxifen by anastrozole does not present higher recurrence risk.

The DPWG also elaborated a guide of recommendation directed to poor metabolizer genotypes $\left({ }^{*}{ }^{*} 8\right.$, $\left.{ }^{*} 11{ }^{*} 16,{ }^{*} 19-{ }^{*} 21,{ }^{*} 38,{ }^{*} 40,{ }^{*} 42\right)$ and intermediate metabolizer genotypes [two reduced activity alleles $\left({ }^{*}\right.$, $\left.{ }^{*} 10,{ }^{*} 17,{ }^{\star} 29,{ }^{*} 36,{ }^{*} 41\right)$ or one active allele $\left({ }^{*} 1,{ }^{*} 2,{ }^{*} 33,{ }^{*} 35\right)$ and one inactive $\left({ }^{*} 3-{ }^{*} 8,{ }^{*} 11-{ }^{*} 16,{ }^{*} 19-{ }^{*} 21,{ }^{*} 38,{ }^{*} 40\right.$, $\left.{ }^{*} 42\right)$ or one inactive allele $\left({ }^{*} 3-^{*} 8,{ }^{*} 11^{*} 16,{ }^{*} 19-{ }^{*} 21,{ }^{*} 38,{ }^{*} 40,{ }^{*} 42\right)$ and one reduced activity allele $\left({ }^{*} 9,{ }^{*} 10,{ }^{*} 17\right.$, $\left.{ }^{*} 29,{ }^{*} 36,{ }^{*} 41\right)$ and one inactive $\left({ }^{*}{ }^{*}{ }^{*} 8,{ }^{*} 11^{*} 16,{ }^{*} 19-{ }^{*} 21,{ }^{*} 38,{ }^{*} 40,{ }^{*} 42\right)$ allele]. It is recommended the use of aromatase inhibitors in post-menopausal women since higher risk of relapse in breast cancer exists. Also, the concomitant use of CYP2D6 inhibitors must be avoided for intermediate metabolizers ${ }^{[6]}$. 


\section{Guidelines from other professional societies}

Cisplatin is one of the most efficacious chemotherapeutic agent in pediatrics, widely used in the treatment of diverse solid tumors such as neuroblastoma, hepatoblastoma, brain tumors, osteosarcoma and germ cell tumors ${ }^{[45]}$. One of the most important complications of this drug is its risk of ototoxicity that produces permanent bilateral audition loss in $26 \%$ to $90 \%$ of the children treated and $10 \%-25 \%$ of adults ${ }^{[46]}$.

There are several studies that suggest that genetic factors may be involved in ototoxicity, although the results are contradictory and scarce in children ${ }^{[47]}$. Studies of gene variants are related to the cytotoxic effect of cisplatin, where genes such as GSTP1, SOD2 (rs4880), XPC (rs2228001), XPD (rs1799793), or genes related to transport are involved such as SLC family (rs4788863) ${ }^{[48-52]}$.

Currently there are no CPIC nor DPWG guidelines for this drug. However, CPNDS has published a guide relating cisplatin ototoxicity with TPMT variants ${ }^{[15]}$, even if the works they refer to are controversial ${ }^{[3-56]}$.

The CPNDS elaborated a guide with recommendations based on the levels of classification for clinical practice. Level A corresponds to high level of evidence (benefits clearly overcome the risks); level B is a recommendation with lower scientific evidence level based on expert opinion; and level $\mathrm{C}$ is mainly based in experts opinion to be used in research context. This guide recommends with level A to perform pharmacogenetics tests in pediatric patients with variants ${ }^{{ }_{2}} 2,{ }^{{ }_{3}} \mathrm{~A},{ }^{{ }^{*}} 3 \mathrm{~B}$ and ${ }^{{ }_{3}} \mathrm{C}$ related with reduced enzyme activity and audition loss ${ }^{[54,55,57-59]}$. There are recommendations with evidence level $\mathrm{C}$ such as the consideration to use otoprotectors in those patients with non-functional variants. Also, the prescription of an alternative treatment when presenting the same efficacy, low toxicity and less ototoxicity ${ }^{[60,61]}$. More frequent monitoring and tracing audiometric control after treatment are also recommended. The impact of these variants related with audition loss is unknown in adult patients ${ }^{[62,63]}$.

There is also a document for doxorubicin. Anthracyclines, as doxorubicin, are among the most effective anticancer treatments, with survival rates over $80 \%$ in some kinds of cancer ${ }^{[64]}$. They are employed in the treatment of children and adults' leukemia, lymphoma and some solid tumors such as breast cancer, ovarian cancer, lung cancer and sarcomas. They act by blocking the synthesis of DNA and RNA by inhibiting topoisomerase II enzyme, thus interrupting DNA replication and transcription and, hence, the replication of cancer cells. Anthracyclines also damage the DNA, proteins and membranes of rapid division cells by creating free oxygen radicals mediated by iron ${ }^{[65,66]}$.

The clinical use of anthracyclines is mainly limited by the high inter-individual variability in anthracyclineinduced cardiotoxicity (ACT) which is dependent on the cumulative dose of the drug and produces toxic effects on heart muscles and their conductivity. ACT occurs in $57 \%$ of patients treated and is still an important limitation of chemotherapy based on anthracyclines ${ }^{[67,68]}$.

There is a guide for doxorubicin elaborated by the $\mathrm{CPNDS}^{[69]}$ in which it is recommended to perform a pharmacogenetic test for the variants $\operatorname{rs} 2229774(\mathrm{G}>\mathrm{A})$ in the gene $R A R G$ and $\operatorname{rs} 17863783(\mathrm{G}>\mathrm{T})$ in the UGT1A ${ }^{*} 4$, considered of high risk for developing ACT and the variant rs7853758 in the SLC28A3 gene whose allele $\mathrm{A}$ is associated with a reduced risk of $\mathrm{ACT}^{[68,70]}$. This allows a stratification of the patients: low-risk patients are recommended a routine echocardiogram and according to the long-term follow-up guidelines of the Children's Oncology Group (COG), a cardiac follow-up every 5 years ${ }^{[7] 1}$. For patients at moderate risk, an increase in the frequency of echocardiograms is recommended, such as the monitoring of cardiotoxicity and, according to the COG, a follow-up every 2 years ${ }^{[71,72]}$. Finally, for high-risk patients, the following recommendations should be considered: the increase in the frequency of annual echocardiograms and monitoring before each administration of anthracyclines as well as the follow-up recommended by the COG guidelines ${ }^{[71]}$; as well as the "aggressive" detection and the examination of risk factors such 
Table 2. Summary of SNP-drug relevant associations according to PharmGKB and drug labels

\begin{tabular}{|c|c|c|c|c|c|c|c|}
\hline Drug & Gene & SNP & $\begin{array}{l}\text { Reference } \\
\text { Genotype }\end{array}$ & $\begin{array}{c}\text { Risk } \\
\text { Genotype }\end{array}$ & $\begin{array}{l}\text { CA Level: } \\
\text { D, E, T, Pk }\end{array}$ & $\begin{array}{l}\text { Drug } \\
\text { label }\end{array}$ & Implications \\
\hline Azathioprine & ITPA & rs7270101 & $\mathrm{AA}$ & $A C, C C$ & $2 \mathrm{~B}: \mathrm{T}$ & $\mathrm{T}$ & Moderate risk of toxicity \\
\hline Capecitabine & UMPS & rs1801019 & $\mathrm{GG}, \mathrm{CG}$ & $\mathrm{CC}$ & $2 \mathrm{~B}: \mathrm{T}$ & A & Moderate risk of toxicity \\
\hline \multirow[t]{6}{*}{ Carboplatin } & ERCC1 & rs11615 & GG & $A A, A G$ & $2 \mathrm{~B}: \mathrm{E}, \mathrm{T}$ & 1 & $\begin{array}{l}\text { Moderate risk of inefficacy } \\
\text { and toxicity }\end{array}$ \\
\hline & ERCC1 & rs3212986 & AA & $A C, C C$ & $2 \mathrm{~B}: \mathrm{T}$ & & Moderate risk of toxicity \\
\hline & GSTP1 & rs1695 & GG & $A A, A G$ & $2 A: T$ & & Moderate risk of toxicity \\
\hline & MTHFR & rs1801133 & AA & $A G, G G$ & $2 A: E$ & & Moderate risk of inefficacy \\
\hline & NQO1 & rs1800566 & GG & $A A, A G$ & $2 A: E$ & & Moderate risk of inefficacy \\
\hline & $X R C C 1$ & rs25487 & $\mathrm{CC}$ & $\mathrm{CT}, \mathrm{TT}$ & $2 B: E$ & & Moderate risk of inefficacy \\
\hline \multirow[t]{3}{*}{ Cyclophosphamide } & GSTP1 & rs1695 & $A A, A G$ & GG & $2 \mathrm{~A}: \mathrm{E}, \mathrm{T}$ & I & $\begin{array}{l}\text { Moderate risk of inefficacy } \\
\text { and toxicity }\end{array}$ \\
\hline & SOD2 & rs4880 & AA & $A G, G G$ & 2B: E & & Moderate risk of inefficacy \\
\hline & TP53 & rs1042522 & $\mathrm{CC}$ & $C G, G G$ & $2 \mathrm{~B}: \mathrm{E}, \mathrm{T}$ & & $\begin{array}{l}\text { Moderate risk of inefficacy } \\
\text { and toxicity }\end{array}$ \\
\hline \multirow[t]{7}{*}{ Cisplatin } & ERCC1 & rs11615 & GG & $A A, A G$ & $2 \mathrm{~B}: \mathrm{E}, \mathrm{T}$ & I & $\begin{array}{l}\text { Moderate risk of inefficacy } \\
\text { and toxicity }\end{array}$ \\
\hline & ERCC1 & rs3212986 & AA & $A C, C C$ & $2 \mathrm{~B}: \mathrm{T}$ & & Moderate risk of toxicity \\
\hline & GSTP1 & rs1695 & AA & $A G, G G$ & $2 \mathrm{~B}: \mathrm{T}$ & & Moderate risk of toxicity \\
\hline & NQO1 & rs1800566 & GG & $A A, A G$ & $2 A: E$ & & Moderate risk of inefficacy \\
\hline & TP53 & rs1042522 & $\mathrm{CC}$ & $C G, G G$ & $2 \mathrm{~B}: \mathrm{E}, \mathrm{T}$ & & $\begin{array}{l}\text { Moderate risk of inefficacy } \\
\text { and toxicity }\end{array}$ \\
\hline & $X P C$ & rs2228001 & $\mathrm{TT}$ & $\mathrm{GT}, \mathrm{GG}$ & $1 \mathrm{~B}: \mathrm{T}$ & & High risk of toxicity \\
\hline & $X R C C 1$ & rs25487 & $\mathrm{CC}$ & $\mathrm{CT}, \mathrm{TT}$ & $2 \mathrm{~B}: \mathrm{E}$ & & Moderate risk of inefficacy \\
\hline Doxorubicin & NQO1 & rs1800566 & GG & $A A, A G$ & $2 A: E$ & I & Moderate risk of inefficacy \\
\hline Etoposide & $D Y N C 2 H 1$ & rs716274 & $\mathrm{AA}$ & $A G, G G$ & $2 \mathrm{~B}: \mathrm{T}$ & I & Moderate risk of toxicity \\
\hline $\begin{array}{l}\text { Fentanyl,Metadone, } \\
\text { Morphine,Opioids, } \\
\text { Oxycodone, } \\
\text { Tramadol }\end{array}$ & $A B C B 1$ & rs1045642 & $A A, A G$ & GG & $2 B: D, E$ & * & $\begin{array}{l}\text { Moderate risk of inefficacy. } \\
\text { Consider dose increase }\end{array}$ \\
\hline \multirow[t]{3}{*}{ Fluorouracil } & GSTP1 & rs1695 & $A G, G G$ & AA & $2 A: E$ & A & Moderate risk of inefficacy \\
\hline & TP53 & rs1042522 & $\mathrm{CC}$ & $C G, G G$ & $2 \mathrm{~B}: \mathrm{E}, \mathrm{T}$ & & $\begin{array}{l}\text { Moderate risk of inefficacy } \\
\text { and toxicity }\end{array}$ \\
\hline & UMPS & rs1801019 & $\mathrm{GG}, \mathrm{CG}$ & $\mathrm{CC}$ & $2 \mathrm{~B}: \mathrm{T}$ & & Moderate risk of toxicity \\
\hline \multirow[t]{3}{*}{ Irinotecan } & C8ORF34 & rs1517114 & GG & $\mathrm{CG}, \mathrm{CC}$ & $2 \mathrm{~B}: \mathrm{T}$ & A & Moderate risk of toxicity \\
\hline & SEMA3C & rs7779029 & TT & $\mathrm{CT}, \mathrm{CC}$ & 2B: $\mathrm{T}$ & & Moderate risk of toxicity \\
\hline & UGT1A1 & rs4148323 & GG & GA, AA & $2 \mathrm{~A}$ & & Moderate risk of toxicity \\
\hline \multirow[t]{5}{*}{ Methotrexate } & $A B C B 1$ & rs1045642 & GG & $A G, A A$ & $2 A: T$ & I & Moderate risk of toxicity \\
\hline & ATIC & rs4673993 & $\mathrm{CC}, \mathrm{TC}$ & $\mathrm{TT}$ & $2 B: E$ & & Moderate risk of inefficacy \\
\hline & MTHFR & rs1801133 & GG & $A A, A G$ & $\begin{array}{l}2 A: D, E \\
T\end{array}$ & & Consider dose reduction \\
\hline & MTRR & rs1801394 & $\mathrm{AA}$ & $A G, G G$ & $2 B: T$ & & Moderate risk of toxicity \\
\hline & SLCO1B1 & rs11045879 & $\mathrm{CC}$ & $\mathrm{CT}, \mathrm{TT}$ & $2 A: T$ & & Moderate risk of toxicity \\
\hline Ondansetron & $A B C B 1$ & rs1045642 & AA & $A G, G G$ & $2 A: E$ & I & Moderate risk of inefficacy \\
\hline \multirow[t]{5}{*}{ Oxaliplatin } & ERCC1 & rs11615 & GG & $A A, A G$ & $2 \mathrm{~B}: \mathrm{E}, \mathrm{T}$ & । & $\begin{array}{l}\text { Moderate risk of inefficacy } \\
\text { and toxicity }\end{array}$ \\
\hline & ERCC1 & rs3212986 & AA & $A C, C C$ & $2 \mathrm{~B}: \mathrm{T}$ & & Moderate risk of toxicity \\
\hline & GSTP1 & rs1695 & GG & $A A, A G$ & $2 A: T$ & & Moderate risk of toxicity \\
\hline & NQO1 & rs1800566 & GG & $A A, A G$ & $2 A: E$ & & Moderate risk of inefficacy \\
\hline & $X R C C 1$ & rs25487 & $\mathrm{CC}$ & $\mathrm{CT}, \mathrm{TT}$ & 2B: E & & Moderate risk of inefficacy \\
\hline Paclitaxel & TP53 & rs1042522 & $\mathrm{CC}$ & $C G, G G$ & $2 \mathrm{~B}: \mathrm{E}, \mathrm{T}$ & I & $\begin{array}{l}\text { Moderate risk of inefficacy } \\
\text { and toxicity }\end{array}$ \\
\hline Rituximab & FCGR3A & rs396991 & $C C, A C$ & AA & $2 B: E$ & $\mathrm{~T}$ & Moderate risk of inefficacy \\
\hline \multirow[t]{2}{*}{ Tamoxifen } & CYP2D6 & rs3892097 & $\mathrm{CC}, \mathrm{CT}$ & $\mathrm{TT}$ & $2 A: E$ & $\mathrm{~T}$ & Moderate risk of inefficacy \\
\hline & CYP2D6 & rs3892097 & TT & $\mathrm{CT}, \mathrm{CC}$ & $2 A: T$ & & Moderate risk of toxicity \\
\hline Tegafur & $D P Y D$ & rs67376798 & TT & AA, AT & $1 \mathrm{~A}: \mathrm{T}, \mathrm{Pk}$ & I & High risk of toxicity \\
\hline
\end{tabular}




\begin{tabular}{llllllll} 
& UMPS & $\mathrm{rs} 1801019$ & $\mathrm{GG}, \mathrm{CG}$ & $\mathrm{CC}$ & 2B: $\mathrm{T}$ & $\begin{array}{l}\text { Moderate risk of toxicity } \\
\text { Trastuzumab }\end{array}$ \\
& FCGR2A & $\mathrm{rs} 1801274$ & $\mathrm{AA}$ & $\mathrm{AG}, \mathrm{GG}$ & 2B: $\mathrm{E}$ & $\mathrm{T}$ & $\begin{array}{l}\text { Moderate risk of inefficacy } \\
\text { Vincristine }\end{array}$ \\
\hline
\end{tabular}

${ }^{*}$ As this line describes a group of drugs, no information from a single drug label can be provided. This table lists the SNPs with levels of evidence 1 and 2 for the chemotherapeutic drugs and some others frequently employed in cancer patients (ondansetron and some pain relief drugs), that still have not a published guideline with therapeutic recommendations. The information about the "reference" and "risk" genotypes, with the proposed implications if the patient bears the risk one is provided. "CA" column describes the level of evidence and the way in which the risk genotype affects the drug mechanism ( $D$, dosage; E, efficacy; Pk, pharmacokinetics; $T$, toxicity) and what does the drug label (FDA or EMA) state about performing genetic tests when prescribing that drug ( $T$, testing required or recommended; A, actionable; I, informative), not specifying genes or variants. SNPs related with a set of drugs have not been listed, this table only includes the genes and SNPs directly linked with each individual drug. Date of PharmGKB access 15 January 2019. SNPs: single nucleotide polymorphisms; CA: clinical annotation

as cardiovascular, such as obesity, diabetes, hypertension, coronary artery disease, lipid disorders and peripheral vascular disease ${ }^{[73]}$.

While Table 1 shows the drug-SNP pairs that are currently included in a guideline, Table 2 shows a compilation of the current information according to the three main pillars explained at the initial section of this work. It includes the majority of drugs used in chemotherapy treatments, and some antiemetic and pain relief drugs that reach Clinical Annotations with Levels of Evidence 1 and 2, listed in PharmGKB, but still do not have a therapeutic/dosing guideline published. Some SNPs may not be directly described in PharmGKB Clinical Annotations under a drug name, but instead they can be found under the generic name of that drug's family. For instance, some relevant SNPs assigned to "cisplatin", can only be reached by searching "platinum compounds". The possible genotypes for each SNP are divided into "Reference Genotype" and "Risk Genotype", having defined these groups in agreement with the biological or clinical meaning of each genotype. Not necessarily the positive or negative effects of a given genotype are linked to the most or least frequent variants, respectively. Variant frequencies can vary widely between different ethnical human populations.

The "Implications" column provides an easy-to-use short interpretation of the content in the original resource. The last column of the table shows the existence of a genetic test recommendation in the drug label, according to FDA and/or EMA.

\section{CONCLUSION}

This work aims to summarize and make available to clinicians, in a practical way, the guidelines and recommendations that exist so far with high level of evidence, of germline genetic variants associated with drugs used in the treatment for both pediatric and adult oncology. In this way, our aim is to facilitate the comprehension of the available information for decision making in clinical practice. The big consortia, as well as relevant hospitals' initiatives worldwide, are performing strong efforts to harmonize, to disseminate and to integrate PGx as a real and useful tool for the clinicians' routine ${ }^{[7]}$.

PGx aims to improve patient's life quality, reducing the adverse effects of drugs and improving the effectiveness of these. Approximately $20 \%$ of pediatric oncology patients do not respond to standard treatments, this percentage seems to be even higher in adults, where the available data on the risks and benefits of treatment are scarce. Administered chemotherapeutic schemes include high doses and toxicity risk, leading to a wide variety of side effects. This is often due to the low specificity of therapeutic target and to the treatment intensification. Chemotherapy toxicity is a regular cause of morbidity and mortality in most of these patients, with short- and long-term sequels. At present, there are PGx tests with sufficient evidence to be implemented in clinical practice, regulated by different guides and drug regulatory agencies. So far, most of them are aimed for treatment in adults and only well defined for its use in pediatric oncology in 
a few cases. Under our point of view, CPIC guidelines are currently the ones that reflect the most updated information, evaluating a larger quantity of published data, and reaching more international experts' consensus.

There are still many variants associated with drugs that have not reached sufficient evidence to be implemented in clinical practice due to the lack of consensus in the studies or the disparity of results. For this reason, PGx studies should continue to be carried out in order to reinforce those variants well described and contribute to increase the evidence in those for which, at the moment, the evidence is not high enough to consider their inclusion in clinical practice.

\section{DECLARATIONS}

\section{Acknowledgement}

We would like to thank Desirée Ramal and Vanessa Segura for their support.

\section{Authors' contributions}

Made substantial contributions to conception and design of the work and performed data analysis and interpretation: Olivera G, Sendra L, Herrero MJ, Aliño SF

Provided administrative, technical, and material support, as well as the Clinicians perspective to the work concept: Berlanga P, Gargallo P, Yáñez Y, Urtasun A, Font de Mora J, Castel V, Cañete A

\section{Availability of data and materials}

Not applicable.

\section{Financial support and sponsorship}

This work was supported by Fundación Mutua Madrileña, Ayudas a la Investigación, proyectos en salud 2016 and by Asociación Pablo Ugarte-APU.

\section{Conflicts of interest}

All authors declared that there are no conflicts of interest.

\section{Ethical approval and consent to participate}

Not applicable.

\section{Consent for publication}

Not applicable.

\section{Copyright}

(c) The Author(s) 2019.

\section{REFERENCES}

1. Ross CJD, Visscher H, Rod Rassekh S, Castro-Pastrana LI, Shereck E, et al. Pharmacogenomics of serious adverse drug reactions in pediatric oncology. J Popul Ther Clin Pharmacol 2011;18:134-51.

2. Conyers R, Devaraja S, Elliott D. Systematic review of pharmacogenomics and adverse drug reactions in paediatric oncology patients. Pediatr Blood Cancer 2018;65:e26937.

3. Whirl-Carrillo M, McDonagh EM, Hebert JM, Gong L, Sangkuhl K, et al. Pharmacogenomics knowledge for personalized medicine. Clin Pharmacol Ther 2012;92:414-7.

4. Rodríguez AE, Herrero MJ, Bernal ML, Rojas L, Peiró AM. Personalized medicine into health national services: barriers and potentialities. Drug Metab Pers Ther 2018; doi: 10.1515/dmpt-2018-0017.

5. Caudle KE, Dunnenberger HM, Freimuth RR, Peterson JF, Burlison, JD, et al. Standardizing terms for clinical pharmacogenetic test 
results: consensus terms from the clinical pharmacogenetics implementation consortium (CPIC). Genet Med 2017;19:215-23.

6. Swen JJ, Nijenhuis M, de Boer A, Grandia L, Maitland-Van Der Zee AH, et al. Pharmacogenetics: from Bench to Byte - an update of guidelines. Clin Pharmacol Ther 2011;89:662-73.

7. García-González X, Cabaleiro T, Herrero MJ, McLeod H, López-Fernández LA. Clinical implementation of pharmacogenetics. Drug Metab Pers Ther 2016;31:9-16.

8. U S Food and Drug Administration. Available from: https://www.fda.gov/. [Last accessed on 18 Feb 2019]

9. European Medicines Agency. Available from: https://www.ema.europa.eu/en. [Last accessed on 18 Feb 2019]

10. Pharmaceuticals and Medical Devices Agency. Available from: http://www.pmda.go.jp/english/. [Last accessed on 18 Feb 2019]

11. Drugs and Health Products - Canada.ca. Available from: https:/www.canada.ca/en/health-canada/services/drugs-health-products.html. [Last accessed on 18 Feb 2019]

12. Relling MV, Klein TE. CPIC: Clinical Pharmacogenetics Implementation Consortium of the Pharmacogenomics Research Network. Clin Pharmacol Ther 2011;89:464-7.

13. Swen JJ, Wilting I, de Goede AL, Grandia L, Mulder H, et al. Pharmacogenetics: from Bench to Byte. Clin Pharmacol Ther 2008;83:781-7.

14. Bank PCD, Caudle KE, Swen JJ, Gammal RS, Whirl-Carrillo M, et al. A comparison of the guidelines of the Clinical Pharmacogenetics Implementation Consortium and the Dutch Pharmacogenetics Working Groups. Clin Pharmacol Ther 2018;103:599-618.

15. Lee JW, Pussegoda K, Rassekh SR, Liu G, Hwang S, et al. Clinical practice recommendations for the management and prevention of cisplatin-induced hearing loss using Pharmacogenetic markers. Ther Drug Monit 2016;38:423-31.

16. Gaedigk A, Sangkuhl K, Whirl-Carrillo M, Klein T, Steven Leeder J. Prediction of CYP2D6 phenotype from genotype across world populations. Genet Med 2017;19:69-76.

17. Relling MV, Gardner EE, Sandborn WJ, Schmiegelow K, Pui CH, et al. Clinical Pharmacogenetics Implementation Consortium guidelines for thiopurine methyltransferase genotype and thiopurine dosing. Clin Pharmacol Ther 2011;89:387-91.

18. Relling MV, Gardner EE, Sandborn WJ, Schmiegelow K, Pui CH, et al. Clinical pharmacogentics implementation consortium guidelines for thiopurine methyltransferase genotype and thiopurine dosing: 2013 Update. Clin Pharmacol Ther 2013;93:324-5.

19. Relling MV, Schaw M, Whirl-Carrillo M, Suarez-Kurtz G, Pui CH, et al. Clinical Pharmacogenetics Implementation Consortium (CPIC) guideline for thiopurine dosing based on TPMT and NUDT15 genotypes: 2018 update. Clin Pharmacol Ther 2018; doi: 10.1002/ cpt.1304.

20. Amstutz U, Henricks LM, Offer SM, Barbarino J, Schellens JHM, et al. Clinical Pharmacogenetics Implementation Consortium (CPIC) Guideline for Dihydropyrimidine Dehydrogenase Genotype and Fluoropyrimidine Dosing: 2017 Update. Clin Pharmacol Ther 2018;103:210-6.

21. Bell GC, Caudle KE, Whirl-Carrillo M, Gordon RJ, Hikino K, et al. Clinical Pharmacogenetics Implementation Consortium (CPIC) guideline for CYP2D6 genotype and use of ondansetron and tropisetron. Clin Pharmacol Ther 2017;102:213-8.

22. Goetz MP, Sangkuhl K, Guchelaar HJ, Schwab M, Province M, et al. Clinical Pharmacogenetics Implementation Consortium (CPIC) guideline for CYP2D6 and Tamoxifen therapy. Clin Phramacol Ther 2018;103:770-7.

23. Alsous M, Yousef AM, Abdel Jalil M, Zawiah M, Yacoub S, et al. Genetic Polymorphism of Thiopurine S-methyltransferase in Children with Acute Lymphoblastic Leukemia in Jordan. Asian Pac J Cancer Prev 2018;19:199-205.

24. Bradford K, Shih DQ. Optimizing 6-mercaptopurine and azathioprine therapy in the management of inflammatory bowel disease. World J Gastroenterol 2011;17:4166-73.

25. Moriyama T, Nishii R, Perez-Andreu V, Yang W, Klussmann FA, et al. NUDT15 polymorphisms alter thiopurine metabolism and hematopoietic toxicity. Nat Genet 2016;48:367-73.

26. Yang SK, Hong M, Baek J, Choi H, Zhao W, et al. A common missense variant in NUDT15 confers susceptibility to thiopurine-induced leukopenia. Nat Genet 2014;46:1017-20.

27. Chiengthong K, Ittiwut C, Muensri S, Sophonphan J, Sosothikul D, et al. NUDT15 c.415C $>$ T increases risk of 6-mercaptopurine induced myelosuppression during maintenance therapy in children with acute lymphoblastic leukemia. Haematologica 2016;101:e24-6.

28. Meulendijks D, Henricks LM, Sonke GS, Deenen MJ, Froehlich TK, et al. Clinical relevance of DPYD variants c.1679T >G, c.1236G $>$ A/ HapB3, and c. $1601 \mathrm{G}>\mathrm{A}$ as predictors of severe fluoropyrimidine-associated toxicity: a systematic review and meta-analysis of individual patient data. Lancet Oncol 2015;16:1639-50.

29. van Kuilenburg AB. Dihydropyrimidine dehydrogenase and the efficacy and toxicity of 5-fluorouracil. Eur J Cancer 2004;40:939-50.

30. Liu X, Cheng D, Kuang Q, Liu G, Xu W. Association between UGT1A1*28 polymorphisms and clinical outcomes of irinotecan-based chemotherapies in colorectal cancer: a meta-analysis in Caucasians. PLoS One 2013;8:e58489.

31. Brandi G, Dabard J, Raibaud P, Di Battista M, Bridonneau C, et al. Intestinal microflora and digestive toxicity of irinotecan in mice. Clin Cancer Res 2006;12:1299-307.

32. Lévesque E, Bélanger AS, Harvey M, Couture F, Jonker D, et al. Refining the UGT1A haplotype associated with irinotecan-induced hematological toxicity in metastatic colorectal cancer patients treated with 5-fluorouracil/irinotecan-based regimens. J Pharmacol Exp Ther 2013;345:95-101.

33. Gammal RS, Court MH, Haidar CE, Iwuchukwu OF, Gaur AH, et al. Clinical Pharmacogenetics Implementation Consortium (CPIC) Guideline for UGT1A1 and Atazanavir Prescribing. Clin Pharmacol Ther 2016;99:363-9.

34. Etienne-Grimaldi MC, Boyer JC, Thomas F, Quaranta S, Picard N, et al. UGT1A1 genotype and irinotecan therapy: general review and implementation in routine practice. Fundam Clin Pharmacol 2015;29:219-37.

35. Kovac AL. Comparative Pharmacology and guide to the use of the serotonin 5-HT3 receptor antagonists for postoperative nausea and 
vomiting. Drugs 2016;76:1719-35.

36. Sanwald P, David M, Dow J. Characterization of the cytochrome P450 enzymes involved in the in vitro metabolism of dolasetron. Comparison with other indole-containing 5-HT3 antagonists. Drug Metab Dispos 1996;24:602-9.

37. Bloomer JC, Baldwin SJ, Smith GJ, Ayrton AD, Clarke SE, et al. Characterisation of the cytochrome P450 enzymes involved in the in vitro metabolism of granisetron. Br J Clin Pharmacol 1994;38:557-66.

38. Gaedigk A, Simon S, Pearce R, Bradford LD, Kennedy MJ, et al. The CYP2D6 activity score: translating genotype information into a qualitative measure of phenotype. Clin Pharmacol Ther 2008;83:234-42.

39. Sanchez Spitman AB, Moes DJAR, Gelderblom H, Dezentje VO, Swen JJ, et al. Effect of CYP3A4*22, CYP3A5*3, and CYP3A combined genotypes on tamoxifen metabolism. Eur J Clin Pharmacol 2017;73:1589-98.

40. Desta Z, Ward BA, Soukhova NV, Flockhart DA. Comprehensive evaluation of tamoxifen sequential biotransformation by the human cytochrome P450 system in vitro: prominent roles for CYP3A and CYP2D6. J Pharmacol Exp Ther 2004;310:1062-75.

41. Thota K, Prasad K, Basaveswara RMV. Detection of cytochrome P450 polymorphisms in breastcancer patients may impact on tamoxifen therapy. Asian Pac J Cancer Prev 2018;19:343-50.

42. Early Breast Cancer Trialists' Collaborative Group (EBCTCG). Aromatase inhibitors versus tamoxifen in early breast cancer: patientlevel meta-analysis of the randomised trials. Lancet 2015;386:1341-52.

43. Maor R, Sara JDS, Wanous AA, Maor E, Pruthi S, et al. Attenuated peripheral endothelial function among women treated with aromatase inhibitors for breast cancer. Coron Artery Dis 2018;29:687-93.

44. Hertz DL, Deal A, Ibrahim JG, Walko CM, Weck KE, et al. Tamoxifen dose escalation in patients with diminished CYP2D6 activity normalizes endoxifen concentrations without increasing toxicity. Oncologist 2016;21:795-803.

45. Ho GY, Woodward N, Coward JIG. Cisplatin versus carboplatin: comparative review of therapeutic management in solid malignancies. Crit Rev Oncol Hematol 2016;102:37-46.

46. Lui G, Bouazza N, Denoyelle F, Moine M, Brugières L, et al. Association between genetic polymorphisms and platinum-induced ototoxicity in children. Oncotarget 2018;9:30883-93.

47. Langer T, am Zehnhoff-Dinnesen A, Radtke S, Meitert J, Zolk O. Understanding platinum-induced ototoxicity. Trends Pharmacol Sci 2013;34:458-69.

48. Liberman PHP, Goffi-Gomez MVS, Schultz C, Jacob PL, de Paula CAA, et al. Contribution of the GSTP1 c.313A >G variant to hearing loss risk in patients exposed to platin chemotherapy during childhood. Clin Transl Oncol 2018; doi: 10.1007/s12094-018-1964-7.

49. Brown AL, Lupo PJ, Okcu MF, Lau CC, Rednam S, et al. SOD2 genetic variant associated with treatment-related ototoxicity in cisplatin-treated pediatric medulloblastoma. Cancer Med 2015;4:1679-86.

50. Lopes-Aguiar L, Costa EFD, Nogueira GAS, Lima TRP, Visacri MB, et al. XPD c.934G $>$ A polymorphism of nucleotide excision repair pathway in outcome of head and neck squamous cell carcinoma patients treated with cisplatin chemoradiation. Oncotarget 2017;8:16190-201.

51. Drögemöller BI, Monzon JG, Bhavsar AP, Borrie AE, Brooks B, et al. Association between SLC16A5 genetic variation and cisplatininduced ototoxic effects in adult patients with testicular cancer. JAMA Oncol 2017;3:1558-62.

52. Lanvers-Kaminsky C, Sprowl JA, Malath I, Deuster D, Eveslage M, et al. Human OCT2 variant c.808G $>$ T confers protection effect against cisplatin-induced ototoxicity. Pharmacogenomics 2015;16:323-32.

53. Ross CJD, Katzov-Eckert H, Dubé MP, Brooks B, Rassekh SR, et al. Genetic variants in TPMT and COMT are associated with hearing loss in children receiving cisplatin chemotherapy. Nat Genet 2009;41:1345-9.

54. Pussegoda K, Ross CJ, Visscher H, Yazdanpanah M, Brooks B, et al. Replication of TPMT and ABCC3 genetic variants highly associated with cisplatin-induced hearing loss in children. Clin Pharmacol Ther 2013;94:243-51.

55. Yang JJ, Lim JYS, Huang J, Bass J, Wu J, et al. The role of inherited TPMT and COMT genetic variation in cisplatin-induced ototoxicity in children with cancer. Clin Pharmacol Ther 2013;94:252-9.

56. Thiesen S, Yin P, Jorgensen AL, Zhang JE, Manzo V, et al. TPMT, COMT and ACYP2 genetic variants in paediatric cancer patients with cisplatin-induced ototoxicity. Pharmacogenet Genomics 2017;27:213-22.

57. Oliveira E, Quental S, Alves S, Amorim A, Prata MJ. Do the distribution patterns of polymorphisms at the thiopurine S-methyltransferase locus in sub-Saharan populations need revision? Hints from Cabinda and Mozambique. Eur J Clin Pharmacol 2007;63:703-6.

58. Hagleitner MM, Coenen MJH, Patino-Garcia A, De Bont ESJM, Gonzalez-Neira A, et al. Influence of genetic variants in TPMT and COMT associated with cisplatin induced hearing loss in patients with cancer: two new cohorts and a meta-analysis reveal significant heterogeneity between cohorts. PLoS One 2014;9:e115869.

59. Krynetski E, Evans WE. Drug methylation in cancer therapy: lessons from the TPMT polymorphism. Oncogene 2003;22:7403-13.

60. Stern JW, Bunin N. Prospective study of carboplatin-based chemotherapy for pediatric germ cell tumors. Med Pediatr Oncol 2002;39:163-7.

61. Shaikh F, Nathan PC, Hale J, Uleryk E, Frazier L. Is there a role for carboplatin in the treatment of malignant germ cell tumors? A systematic review of adult and pediatric trials. Pediatr Blood Cancer 2013;60:587-92.

62. Kolinsky DC, Hayashi SS, Karzon R, Mao J, Hayashi RJ. Late onset hearing loss: a significant complication of cancer survivors treated with cisplatin containing chemotherapy regimens. J Pediatr Hematol Oncol 2010;32:119-23.

63. Grewal S, Merchant T, Reymond R, McInerney M, Hodge C, et al. Auditory late effects of childhood cancer therapy: a report from the Children's Oncology Group. Pediatrics 2010;125:e938-50.

64. Ellison LF, Pogany L, Mery LS. Childhood and adolescent cancer survival: a period analysis of data from the Canadian Cancer Registry. Eur J Cancer 2007;43:1967-75. 
65. Scully RE, Lipshultz SE. Anthracycline cardiotoxicity in long-term survivors of childhood cancer. Cardiovascular Toxicology 2007;7:122-8.

66. Minotti G. Anthracyclines: molecular advances and pharmacologic developments in antitumor activity and cardiotoxicity. Pharmacol Rev 2004;56:185-229.

67. Cortés-Funes H, Coronado C. Role of anthracyclines in the era of targeted therapy. Cardiovasc Toxicol 2007;7:56-60.

68. Aminkeng F, Bhavsar AP, Visscher H, Rassekh SR, Li Y, et al. A coding variant in RARG confers susceptibility to anthracyclineinduced cardiotoxicity in childhood cancer. Nat Genet 2015;47:1079-84.

69. Aminkeng F, Ross CJD, Rassekh SR, Hwang S, Rieder MJ, et al. Recommendations for genetic testing to reduce the incidence of anthracycline-induced cardiotoxicity. Br J Clin Pharmacol 2016;82:683-95.

70. Visscher H, Ross CJD, Rassekh SR, Sandor GSS, Caron HN, et al. Validation of variants in SLC28A3 and UGT1A6 as genetic markers predictive of anthracycline-induced cardiotoxicity in children. Pediatr Blood Cancer 2013;60:1375-81.

71. Ryerson AB, Border WL, Wasilewski-Masker K, Goodman M, Meacham L, et al. Assessing anthracycline-treated childhood cancer survivors with advanced stress echocardiography. Pediatr Blood Cancer 2015;62:502-8.

72. Tuzovic M, Wu PT, Kianmahd S, Nguyen KL. Natural history of myocardial deformation in children, adolescents, and young adults exposed to anthracyclines: systematic review and meta-analysis. Echocardiography 2018;35:922-34.

73. Rose-Felker K, Border WL, Hong BJ, Chow EJ. Cardio-oncology related to heart failure: pediatric considerations for cardiac dysfunction. Heart Failure Clinics 2017;13:311-25.

74. Kaudle KE, Keeling NJ, Klein TE, Whirl-Carrillo M, Pratt VM, et al. Standardization can accelerate the adoption of pharmacogenomics: current status and the path forward. Pharmacogenomics 2018;19:847-60. 